pocas semanas organizar por cuenta propia un viaje a Alaska.

Lo entristeció la vida en Brevig. En 45 años, la hermosa comunidad que practicaba técnicas ancestrales de caza y pesca de ballenas, había terminado sometida a la beneficencia. Familias enteras vivían en el ocio recibiendo dinero de una compañía petrolera que les pagaba por la explotación de sus tierras. Repuesto de la impresión, restableció contactos, repitió la labor de convencimiento que llevó a cabo en esos mismos parajes en su juventud y con la ayuda de cuatro entusiastas esquimales cavó hasta encontrar el cuerpo bien conservado de una mujer de 40 años de la que pudo tomar muy buenas muestras de tejido pulmonar. A los pocos días Taubenberger las tuvo en sus manos y una semana después identificaba las secuencias del afamado virus.

Hoy la pandemia de influenza de 1918 empieza a recuperar el sitio que le corresponde en la historia de la salud pública. Las pandemias de 195758 y 1968-69 contribuyeron sin duda a sacar del ostracismo a tan extraordinario evento. Lo mismo hicieron la amenaza infundada de influenza porcina de 1976 y, más recientemente, los trabajos de Hultin y Taubenberger $Y$ ahora la posible pandemia de influenza aviar ha puesto en boca de literalmente todos el tema de las grandes gripes. El libro de Kolata, que también contribuye a remediar el olvido, no pudo haberse publicado en momento mejor.

Octavio Gómez Dantés ocogomez@yahoo.com

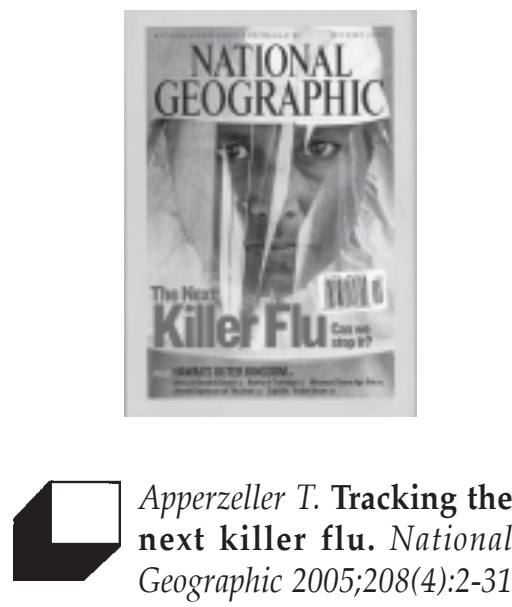

\section{La pandemia que viene}

La amenaza conocida a la salud más sería que enfrenta el mundo es la gripe aviar

Lee Jong-Wook

Director de la

Organización Mundial de la Salud

Sólo el SIDA ha generado un nivel de atención semejante. Y esta pandemia todavía no llega. Revistas tan diversas como Nature, Time, Foreign Affairs
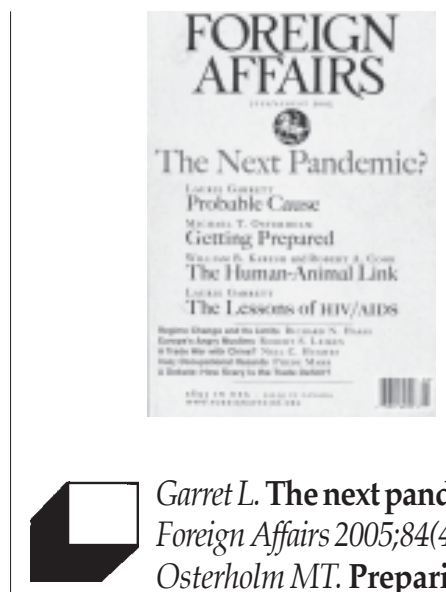

Garret $L$. The next pandemic? Foreign Affairs 2005;84(4):3-23. Osterholm MT. Preparing for the next pandemic. Foreign Affairs 2005;84(4):24-37. Karesh WB, Cook Ra. The human-animal link. Foreign Affairs 2005;84(4):38-50.

Garret $L$. The lessons of HIV. Foreign Affairs 2005;84(4):51-65.

y National Geographic le han dedicado sus portadas y artículos principales, y no ha habido periódico en el mundo que no haya publicado un suplemento especial sobre el tema. No es para menos, si las predicciones más sobrias se cumplen, la pandemia de gripe aviar que tanto se anuncia producirá enormes daños a la salud y trastornos económicos sin precedentes.

De 2003 a la fecha, en el sudeste asiático, China, Hong Kong e Indo- nesia han fallecido de influenza aviar poco más de 60 personas y han muerto o han tenido que sacrificarse alrededor de 150 millones de aves. Los daños económicos ascendieron, sólo en el 2004, a más de 10 mil millones de dólares. Y este último verano el virus H5N1 empezó a extenderse hacia occidente. Se detectó ya en Mongolia, Tibet, Siberia, Kazakhistán, Turquía, Rumania, Rusia, Suecia y Gran Bretaña. 
Los cálculos sobre el número de muertes que esta pandemia podría producir varían considerablemente. Los escenarios más conservadores de la Organización Mundial de la Salud hablan de entre dos y siete millones de decesos. Laurie Garrett anticipa hasta 16 millones de muertes sólo en Estados Unidos. Los escenarios mas dramáticos arrojan cifras de entre 180 y 360 millones de fallecimientos, cinco veces más que los producidos por el SIDA hasta la fecha. Del lado cauteloso, otros grupos de científicos aseguran que el número de muertes será más bien similar al de la pandemia de influenza asiática de 1957 o al del brote de gripe de Hong Kong de 1968, que produjeron dos y un millón de muertes, respectivamente, cifras muy lejanas a las de la pandemia de influenza de 1918, que produjo por lo menos 60 millones de víctimas.

Se prevé que el virus se trasladará de las aves a los cerdos y de allí al ser humano. De hecho, parte de este recorrido ya se dio. El virus H5N1 pasó de los patos en China a los pollos en Hong Kong, en donde las autoridades ordenaron el sacrificio de prácticamente todas estas aves de la ciudad, lo que pareció detener el brote. El virus, sin embargo, retrocedió a China, en donde se le volvió a detectar en aves acuáticas y, poco después, en aves domésticas y pollos. De allí se trasladó a Vietnam y Tailandia, al tiempo que su virulencia se incrementaba. En 2005 se detectó en puercos en Indonesia y, al parecer, China y Vietnam.

Las condiciones en las que este virus está mutando son particularmente favorables para su eventual transmisión al ser humano. Unas cuantas cifras así lo indican. En China, por ejemplo, en la última pandemia de 1968-1969 había 12.3 millones de pollos y 5.2 millones de cerdos. Hoy hay 13 mil millones de pollos y 508 millones de puercos. Los incrementos en el resto de Asia son similares. Si tomamos en cuenta además que de 1980 a la fecha se ha triplica- do el número de viajeros internacionales para alcanzar un promedio diario de tres millones, las posibilidades de una pandemia devastadora resultan enormes.

Nuestra capacidad de respuesta frente una epidemia de esta naturaleza al parecer es limitada. El antiviral que pudiera utilizarse para combatir la influenza, el oseltamivir, tiene una eficacia más bien modesta según un metaanálisis recientemente publicado por el British Medical Journal. Es un hecho que no previene la infección; al parecer se limita a reducir en un día la duración de la enfermedad. Andrew Cole, del Hospital Universitario de St. George en Londres, se pregunta: y si esto es cierto, ¿nos sirve de algo?

Y luego está la vacuna, que también tiene sus problemas. En primer lugar, no puede producirse hasta que surja el virus específico responsable de esta potencial pandemia. En segundo lugar está el problema de la velocidad a la que esta vacuna puede producirse. Incluso en los escenarios más optimistas se piensa que varios millones de personas se infectarán antes de que la vacuna esté lista. En tercer lugar, está el problema de las cantidades que podrían llegar a generarse ya que son muy pocos los países (Alemania, Australia, Canadá, Estados Unidos, Francia, Holanda, Italia, Japón y Reino Unido) que cuentan con la capacidad para producirla. Otro de los problemas es la distribución: ¿será el mundo capaz de distribuir este escasísimo recurso entre aquellos que más lo necesitan o prevalecerá el egoísmo y la irracionalidad?

La mayor de las debilidades se ubica en la atención a los casos. Aquí la conclusión es contundente: no hay país en el mundo con la infraestructura hospitalaria y el personal necesarios para atender la cantidad de casos de influenza aviar que pudieran presentarse

Hay quien piensa que se está exagerando la magnitud del peligro. Paul Ewald, biólogo evolucionista de la
Universidad de Louisville, Kentucky, asegura que contamos con sistemas de respuesta mucho más eficientes que limitarán los daños a la salud. Conocemos mucho mejor que hace tres décadas la manera en que se propagan este tipo de infecciones; contamos con mejores sistemas de información, y los sistemas de comunicación son infinitamente más eficientes. En donde el optimismo de Ewald parece exagerado, es en su confianza en los nuevos medicamentos antivirales y las vacunas. Como se menciona más atrás, los antivirales, en general, y los medicamentos contra la influenza, en particular, tienen una eficacia pobre, y la tecnología para la producción de vacunas contra la influenza no ha avanzado gran cosa en los últimos 30 años.

En el ámbito económico las predicciones no son más alentadoras. En el momento en que surjan evidencias de que el virus se transmite de persona a persona y tiene una alta letalidad, se implantarán cuarentenas y restricciones de viaje que paralizarán la economía mundial. Y la razón de esto, según Michael Osterlholm, infectólogo de la Universidad de Minnesota, es relativamente simple: "Somos mucho más vulnerables hoy porque en el pasado éramos más autosuficientes".

Las medidas de aislamiento no han probado su eficacia en la diseminación de la influenza por el simple hecho de que se trata de una enfermedad extraordinariamente contagiosa. Pero ¿qué gobierno va a resistir la tentación de implantar cuarentenas? Ya en abril de 2005 el Presidente Bush emitió una orden ejecutiva autorizando su uso en Estados Unidos y permitiendo el aislamiento de los visitantes internacionales sospechosos de portar el virus de la influenza. Recordemos el caso del SARS, que siendo mucho menos peligroso, prácticamente paralizó el comercio y los viajes en Asia durante tres meses.

Particularmente sensibles son las consecuencias en el abasto de productos y servicios que se distribuyen ex- 
clusivamente a través de redes internacionales y que son esenciales para una economía. Destacan dentro de éstos ciertos alimentos y medicamentos. Muchas otras industrias que requieren de contacto humano cercano, como las escuelas, los cines y los restaurantes, también se verán afectados. ¿Y qué decir de los efectos en la productividad laboral provocados por el daño a la salud de los trabajadores? Con el SARS, sólo en la región Asia-Pacífico, se registraron pérdidas económicas por más de 40 mil millones de dólares. Ahora hay quien habla de una posible recesión mundial.

A estas alturas ¿qué conclusiones podríamos sacar de esta amenaza? En primer lugar, que vivimos en una nueva era bio-cultural, como lo señala Karlen, en la que las pandemias habrán de ser el pan nuestro de cada día.

En segundo lugar, que no contamos con la infraestructura, los recur- sos humanos, la tecnología y las habilidades organizativas suficientes y necesarios para hacer frente a este tipo de retos. Requerimos, no cabe duda, de mayor inversión en sistemas de vigilancia y control epidemiológico; más investigación en infecciones virales; mayor inversión en nuevos medicamentos y vacunas que nos permitan prevenir y tratar la influenza, y mayores y mejores mecanismos de colaboración internacional en materia de prevención y control de epidemias.

En este sentido los esfuerzos que se están haciendo son loables y contribuirán, no importa lo que suceda con esta amenaza, a fortalecer nuestra capacidad de respuesta.

Finalmente es importante reconocer que los gobiernos y las sociedades, en colaboración con los medios de comunicación, deben discutir de manera abierta y franca la necesidad de atender de manera racional y respon- sable estas contingencias, que habrán de repetirse, de tal manera que en las respuestas nacionales e internacionales prevalezcan no las posturas egoístas y contraproducentes, sino la calma, y el sentido y bien comunes.

Una última reflexión. Es posible que la próxima pandemia de influenza no sea tan devastadora como se anticipa. Si así sucede y terminamos siendo testigos de una pandemia de daños mínimos, no nos quedará sino preguntarnos si el miedo no hizo del mundo entero, incluyendo a la Organización Mundial de la Salud, una presa fácil. Quedará, sin embargo, el consuelo de un sistema mundial de vigilancia epidemiológica robustecido.

Octavio Gómez Dantés ocogomez@yahoo.com 